\title{
Initial and Final Status of the Patients with Niemann Pick $A$ and B: Ege University Experience
}

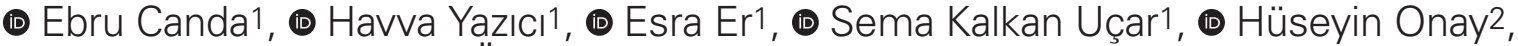 \\ ๑ Eser Sözmen3, ๑ Ferda Özkınay2, ๑ Mahmut Çoker1 \\ ${ }^{1}$ Ege University Faculty of Medicine, Department of Pediatrics, Division of Pediatric Metabolism and Nutrition, Izmir, Turkey \\ 2 Ege University Faculty of Medicine, Department of Genetics, Izmir, Turkey \\ ${ }^{3}$ Ege University Faculty of Medicine, Department of Biochemistry, Izmir, Turkey
}

\begin{abstract}
Aim: Niemann-Pick disease (NPD) is a lysosomal storage disease caused by an insufficient activity of acid sphingomyelinase (ASM) resulting in the accumulation of sphingomyelin. Type A is an infantile neurovisceral fatal form characterized by hepatosplenomegaly and rapidly progressive neurological deterioration, while the Type B nonneuronopathic disease presents visceral form and sufferers usually survive into adulthood.

Materials and Methods: Here we present clinical and molecular findings for 19 patients with NPD A/B.

Results: Nineteen patients with ASM deficiency were enrolled in our study. Nine of them were female and ten patients were male. The median age of the patients was 7.5 years (minimum-maximum: 1-57 years), the median age at diagnosis was 3 years (minimum-maximum: 6 months- 56 years). The median length of the follow up period was 4.07士3.8 years (range: 1 month-14 years). Eighteen patients had hepatosplenomegaly, one patient had splenomegaly. Pulmonary involvement was detected in 10 patients. Six patients died during follow up.

Conclusion: Patients with Niemann Pick A/B have a high mortality and morbidity rate. There is a need for a safe and effective therapy for patients with NPD A/B to reduce splenomegaly, to improve liver and respiratory function and to reduce the rate of mortality and morbidity.

Keywords: Hepatosplenomegaly, interstitial pulmonary disease, cytopenia, acid sphingomyelinase
\end{abstract}

\section{Introduction}

Niemann-Pick disease (NPD) is a lysosomal storage disease caused by the insufficient activity of acid sphingomyelinase (ASM) resulting in the accumulation of sphingomyelin in the monocyte-macrophage system. Type A (MIM \#257200) is an infantile neurovisceral fatal form characterized by hepatosplenomegaly and rapidly progressive neurological deterioration while Type B (MIM \#207616) is non-neuronopathic form. Type $B$ is characterized by visseromegaly and sufferers usually survive into adulthood (1). The NPD-Type B (NPD-B) phenotypic spectrum among individuals varies widely and the age of onset may be from early childhood to adulthood. Hepatosplenomegaly is the most frequent clinical finding in NPD-B and secondary hypersplenism, growth restriction, pulmonary involvement and mild liver failure can also be seen $(2,3)$ The most consistent laboratory finding is an abnormal lipid profile (i.e. high triglycerides and low density lipoprotein-cholesterol, low high density lipoprotein-cholesterol) and a history of the coronary arterial disorder may also be found $(4,5)$. The lungs are frequently affected in NPD-B patients. In some patients, eye examination revealed distinct cherry red spot. There may also be a reddish-brown halo surrounding the macula in the eyes of some patients. Other common findings are fatigue, bone and joint pain and osteopenia. Thrombocytopenia and leukopenia typically worsen over time. NPD-A patients exhibit hepatosplenomegaly and failure to thrive within the first year 
of life. A cherry red spot in the eye is present in $50 \%$ of these patients. Type $A$ is characterized by a rapidly progressive neurodegeneration with profound hypotonia (6). Patients with intermediate findings between NPD-A and NPD-B have been described (6). In 1967 Kampine et al. (7) described the first enzymatic determination of these disorders by determining enzyme activities in peripheral blood leukocytes. The ASM gene (SMPD1; MIM \#607608) contains 6 exons and is located on chromosome 11p15.1-11p15.4 (1). It is well documented that Type A-causing SMPD1 mutations occur more frequently among patients with Ashkenazi Jewish heritage than in the general population (8). Our aim is to discuss the clinical and molecular findings of patients with NPD A/B who were followed up at Ege University Faculty of Medicine, Pediatric Metabolism and Nutrition Unit.

\section{Materials and Methods}

Nineteen patients who were diagnosed with Niemann Pick A and B at Ege University Faculty of Medicine, Department of Pediatric Metabolism and Nutrition Unit were included in this study. The patients' demographical features including age, sex, age at diagnosis, clinical findings; ophthalmological examination, organomegaly, pulmonary and gastrointestinal complications and their surgical histories were noted. We collected biochemical data to determine the function of their organs (liver function, renal function, lipoprotein levels). Liver and/or bone marrow biopsy results which had been done during the diagnostic period and acid sphingomyelinase enzyme levels were evaluated. SMPD1 gene analysis was also recorded. Where available, radiological information was also included. A consent form was filled out by all participants.

\section{Statistical Analysis}

Statistical analysis was performed using "SPSS for Windows 22" software. The descriptive values of demographic and clinical parameters were analysed. Categorical variables are given as case number and percentage. Descriptive statistics are shown as mean \pm standard deviation (SD) or median (minimum-maximum) for numeric variables.

\begin{tabular}{|c|c|c|c|c|c|c|c|}
\hline $\begin{array}{l}\text { Patient } \\
\text { no }\end{array}$ & \begin{tabular}{|l|} 
Age \\
(years)
\end{tabular} & $\begin{array}{l}\text { Age at } \\
\text { diagnosis }\end{array}$ & $\begin{array}{l}\text { Gender } \\
\text { consanguinity }\end{array}$ & Current status & $\begin{array}{l}\text { Follow up } \\
\text { period (years) }\end{array}$ & Clinical findings & $\begin{array}{l}\text { Clinical based } \\
\text { NPD Type }\end{array}$ \\
\hline 1 & 7.5 & 1 years & $\mathrm{M} /$ first degree cousin & Alive & 7.6 & HSM, bleeding CRS, ILD & $B$ \\
\hline 2 & 7 & 1.5 years & F/first degree cousin & Alive & 7 & HSM & $B$ \\
\hline 3 & - & 3 months & F/first degree cousin & Deceased (16 months) & 1.3 & HSM, ILD, DD & A \\
\hline 4 & 21 & 9 years & F/first degree cousin & Alive & 14 & $\begin{array}{l}\text { HSM, bleeding, ILD, psychiatric } \\
\text { symptoms }\end{array}$ & $B$ \\
\hline 5 & * & 5.5 years & $\mathrm{M} /$ first degree cousin & Deceased & 8 & HSM, bleeding, ILD & B (severe) \\
\hline 6 & * & 3 years & $\mathrm{M} /$ first degree cousin & Deceased & 8 & HSM, bleeding, ILD & B (severe) \\
\hline 7 & 21 & 4 years & $\mathrm{M} /$ first degree cousin & Alive & 7.8 & HSM & $B$ \\
\hline 8 & 16 & 13 years & F/first degree cousin & Alive & 4 & HSM, ILD & $B$ \\
\hline 9 & 28 & 25 years & F/first degree cousin & Alive & 3.8 & HSM, ILD & $B$ \\
\hline 10 & 57 & 56 years & F/first degree cousin & Alive & 2 & HSM, bleeding, CRS & $B$ \\
\hline 11 & 19.5 & 19 years & $\mathrm{M} /$ first degree cousin & Alive & 0.3 & HSM, ILD & $B$ \\
\hline 12 & 1 & 7 years & $\mathrm{M} /$ first degree cousin & Alive & 0.5 & HSM, CRS, ILD, DD & $A / B$ \\
\hline 13 & 7 & 6.5 years & $\mathrm{M} /$ first degree cousin & Alive & 0.5 & HSM & B \\
\hline 14 & 6 & 3 years & F/first degree cousin & Alive & 3.5 & SM & $B$ \\
\hline 15 & - & 6 months & $\mathrm{M} /$ third degree & Deceased ( 3 years old) & 1 & HSM, bleeding, CRS, DD & B (severe) \\
\hline 16 & - & 1 years & M/first degree cousin & Deceased & 0.6 & HSM, CRS, DD & $A$ \\
\hline 17 & - & 6 months & F/first degree cousin & Deceased & 0.08 & HSM, CRS, DD & A \\
\hline 18 & 7.5 & 6 months & F/none & Alive & 2 & HSM & B \\
\hline 19 & 9 & 3.5 years & $\mathrm{M} /$ third degree & Alive & 5.5 & HSM, ILD & $B$ \\
\hline
\end{tabular}

HSM: Hepatosplenomegaly, SM: Splenomegaly, CRS: Cherry red spot, ILD: Interstitial lung disease, DD: Developmental delay, NPD: Niemann-Pick disease, F: Female, M: Male *They died and ages at last-visit were 13 and 11 years respectively 


\section{Results}

Nineteen patients with NPD-A and NPD-B were enrolled in our study. Nine of them were female, ten patients were male. The median age of the patients was 7.5 years (minimummaximum: 1-57 years) the median age at diagnosis was 3 years (minimum-maximum: 6 months- 56 years). The median length of the follow up period was $4.07 \pm 3.8$ years (range: 1 month-14 years). Two patients had low weight SD score (SDS) (-2.15 and -2.32), three patients had growth retardation, height SDS were between -2.31 and -5.2 . Five patients had low weight and height SDS. The weight SDS ranged from -2.05 to -3.06 and the height SDS ranged from -3.03 to -6.7 . Six (31.5\%) patients had bleeding (minor mucosal bleeding) and fifteen (78.9\%) patients had abdominal distension and pain. One $(5.2 \%)$ of our patients had joint pain and a history of the treatment at rheumatology clinics. Eight $(42.1 \%)$ patients had a history of recurrent infections such as bronchiolitis, pneumonia and otitis media. Two (10.4\%) of these (patient 1 and 12) have hearing loss due to recurrent otitis media. Hepatosplenomegaly was detected in 18 (94.7\%) patients. Additionally, one (5.2\%) of the patients had splenomegaly. Cherry red spot was observed in 6 (31.5\%) patients. Pulmonary involvement was determined in 10 $(52.6 \%)$ patients via clinical and radiological findings. Three $(15.7 \%)$ of our patients were diagnosed in adulthood but had a history of abdominal distension and splenomegaly in childhood. Five (26.3\%) patients had developmental delay. The demographical, clinical and diagnostic laboratory findings of the patients are detailed in Table I. Clinical signs and symptoms are given in Figure 1. Liver biopsies were performed on 5 patients and hepatic steatosis and liver fibrosis were detected. Bone marrow biopsies were performed on 10 patients and lipid-laden foam cells were detected. Osteoporosis was detected in one patient. Acid sphingomyelinase enzyme levels were low in all patients. SMPD1 gene analysis was performed on 17 patients in the study. SMPD1 analysis for patient 6 could not be performed. The enzyme levels and SMPD1 gene analysis of the patients are detailed in Table II.

Anemia was detected in 3 patients, thrombocytopenia was detected in 1 patient, bicytopenia (anemia + thrombocytopenia) was detected in 3 patients and pancytopenia was detected in 2 patients as initial findings. There was hypertriglyceridemia

\begin{tabular}{|c|c|c|c|}
\hline Patient no & Acid sphingomyelinase (normal) & SMPD1 gene analysis & Genomic mutation amino acid change \\
\hline 1 & $0.003 \mathrm{nmol} / 17 \mathrm{~h} / \mathrm{mg}$ prot $(7.7 \pm 3.08)$ & c.409T>C/c.409T>C & p.L137P/p.L137P \\
\hline 2 & $1.28 \mathrm{nmol} / 17 \mathrm{~h} / \mathrm{mg} \operatorname{prot}(7.7 \pm 3.08)$ & c.409T>C/c.409T>C & p.L137P/p.L137P \\
\hline 3 & $1.2 \mathrm{nmol} / 17 \mathrm{~h} / \mathrm{mg}$ prot $(7.7 \pm 3.08)$ & c.567delT/c.567delT & p.P189PfsX65/p.P189PfsX65 \\
\hline 4 & $0.5 \mathrm{nmol} / \mathrm{mL} / \mathrm{h}(3.7-21)$ & c.409T>C/c.409T>C & p.L137P/p.L137P \\
\hline $5^{*}$ & $2.9 \mathrm{nmol} / \mathrm{h} / \mathrm{mg}$ prot $(84-270)$ & c.409T>C/c.409T>C & p.L137P/p.L137P \\
\hline $6^{*}$ & $2.3 \mathrm{nmol} / \mathrm{h} / \mathrm{mg}$ prot $(84-270)$ & NA & NA \\
\hline 7 & $0.2 \mu \mathrm{mol} / \mathrm{L} / \mathrm{h}(1-10)$ & c. $482 \mathrm{~T}>\mathrm{C} / \mathrm{c} .482 \mathrm{~T}>\mathrm{C}$ & p.L161P/p.L161P \\
\hline 8 & $0.1 \mathrm{nmol} / \mathrm{mL} / \mathrm{h}(1.3-15)$ & c.409T>C/c.409T>C & p.L137P/p.L137P \\
\hline 9 & $0.45 \mathrm{nmol} / \mathrm{mL} / \mathrm{h}(3.7-21)$ & c.409T>C/c.409T>C & p.L137P/p.L137P \\
\hline 10 & $0.08 \mathrm{nmol} / \mathrm{mL} / \mathrm{h}(1.3-15)$ & c. $847 \mathrm{G}>\mathrm{A} / \mathrm{c} .847 \mathrm{G}>\mathrm{A}$ & p.A283T/p.A283T \\
\hline 11 & $0.2 \mu \mathrm{mol} / \mathrm{L} / \mathrm{h}(>0.9)$ & c. $1652 T>C / c .1652 T>C$ & p.L551P/p.L551P \\
\hline 12 & $0.06 \mathrm{nmol} / \mathrm{mL} / \mathrm{h}(1.3-15)$ & c.573delT/c.573delT & p.S192AfsX65/p.S192AfsX65 \\
\hline 13 & $0.2 \mathrm{nmol} / \mathrm{mL} / \mathrm{h}(1.3-15)$ & NA & NA \\
\hline 14 & $0.18 \mathrm{nmol} / 17 \mathrm{~h} / \mathrm{mg} \operatorname{prot}(7.7 \pm 3.08)$ & c. $528 \mathrm{G}>\mathrm{C} / \mathrm{c} .533 \mathrm{~T}>\mathrm{A}$ & p.W176C/p.I178N \\
\hline 15 & $0.08 \mathrm{nmol} / 17 \mathrm{~h} / \mathrm{mg}$ prot $(7.7 \pm 3.08)$ & c.1755delC/c.1755delC & p.P585PfsX24/p.P585PfsX24 \\
\hline 16 & $0.46 \mathrm{nmol} / 17 \mathrm{~h} / \mathrm{mg} \operatorname{prot}(7.7 \pm 3.08)$ & c.567delT/c.567delT & p.P189PfsX65/p.P189PfsX65 \\
\hline 17 & $0.272 \mu \mathrm{mol} / \mathrm{L} / \mathrm{h}(1-10)$ & c.567delT/c.567delT & p.P189PfsX65/p.P189PfsX65 \\
\hline 18 & $0 \mathrm{nmol} / 17 \mathrm{~h} / \mathrm{mg}$ prot $(7.7 \pm 3.08)$ & c. $409 \mathrm{~T}>\mathrm{C} / \mathrm{c} .1262 \mathrm{~A}>\mathrm{G}$ & p.L137P/p.H421R \\
\hline 19 & $0.66 \mathrm{nmol} / \mathrm{mL} / \mathrm{h}(1.3-15)$ & c. $1552 T>C / c .1552 T>C$ & p.L549P/p.L549P \\
\hline
\end{tabular}

*Sibling, NA: Not applicable 
in 9 patients and hypercholesterolemia in 9 patients. Nine patients had high transaminase levels. During follow up, 8 patients' transaminase levels returned to normal ranges. Complete blood count and other biochemical investigations are shown in Table III. Chitotriosidase activity measurements were performed on 12 patients. The mean chitotriosidase level was $179.3 \pm 234.3 \mathrm{nmol} / \mathrm{mL} / \mathrm{h}$ (normal range: 0-38, minimum-maximum: 8.9-818) and high chitotriosidase levels were detected in 6 patients. Patient 4 developed psychiatric signs and was treated with antipsychotic drugs. Patient 1 had a history of recurrent febrile episodes and was diagnosed with Familial Mediterranean Fever. A homozygous M694V mutation was detected under MEFV gene analysis. He was treated with colchicine. During follow up, bone marrow transplantation was planned for him and he underwent partial splenectomy surgery. Due to donor problems and his parents' decision, Bone marrow transplantation (BMT) was not performed. Pulmonary involvement was frequent in our patients. High-resolution computed tomography analysis was performed on 10 patients and a reticulonodular interstitial pattern was detected. Echocardiography revealed mitral insufficiency in three patients and aortic insufficiency in one patient. Coronary arterial disease was not detected. Six patients died during follow up. The latest status for patient 6 was unavailable at the time of writing. Patient 3 died at the age of 16 months; she was clinically based NPD-A. She had severe developmental delay combined with massive hepatosplenomegaly. She had severe interstitial lung disease and died due to pulmonary complications. Her cranial magnetic resonance imaging investigation revealed bilateral cerebral hemisphere diffuse atrophy. Patient 5 and 6 discontinued their follow up. Their ages at last-visit were 13 and 11 years respectively. We subsequently found out that that they had died. Patients 15 and 17 died during follow up. Patient 15 had developmental delay combined with hepatosplenomegaly and died at home due to an aspiration after vomiting. Patient 16 and 17 discontinued their follow up and were subsequently found to have died.

\section{Discussion}

Acid sphingomyelinase deficiency is a rare disease with an estimated incidence of 0.4 to 0.6 in 100.000 new-borns (6). We have no data for the incidence of ASM deficiency in our country. Due to the high number of consanguineous marriages, a high incidence is suspected. In our study, consanguinity was recorded in 18 patients. Clinically, ASM deficiency has been classified as NPD-A and NPD-B based on the presence or absence of neurological involvement respectively (6). In our study, 4 of our patients had the clinical signs of NPD-A and the other 15 patients had the clinical findings of NPD-B. The first symptom in most patients with NPD-A is hepatosplenomegaly which is typically observed by the age of 3 months. (9). Likewise, hepatosplenomegaly is a consistent feature of NPD-B patients (10). All patients in our study had splenomegaly. Among patients with NPD$B$, there is a broad range of disease severity. Age at clinical presentation can range from early childhood to the fourth or fifth decades of life $(6,9)$. Three of our patients were diagnosed in adulthood but two of them had a history of abdominal distension and splenomegaly in childhood. The diagnosis was delayed. In the literature; growth retardation was shown in $29 \%$ of the patients with NPD-B and was particularly prominent in adolescents. Also, it was shown that weight $Z$ scores were $>-2$ in $15 \%$ of NPD-B patients. We found similar findings; two patients had low weight SDS, three patients had low height SDS and five patients had both low weight and height SDS. NPD-B is most commonly associated with pulmonary involvement, expressed through interstitial lung disease $(10,11)$. In our study, 10 patients had interstitial lung disease. Patient 1 had recurrent pulmonary infections, but during follow up, symptoms became less severe. Patient 3 had a history of respiratory insufficiency. In the literature, several cases with NPD-B presented with evere liver disease (e.g. hepatic failure) were reported (12). In this study, nearly half of the patients had high transaminase levels. One patient died due to liver failure and 3 others had liver failure.

\begin{tabular}{|l|l|l|l|}
\hline Table III. Initial laboratory studies of the patients with Niemann-Pick disease Type A and Type B & Range & Abnormal (\%) \\
\hline Laboratory study & Mean \pm SD & $7.2-14.2$ & $8(42)$ \\
\hline Hemoglobin, g/L & $11.02 \pm 1.8$ & $21-41$ & $8(42)$ \\
\hline Hematocrit, \% & $32.4 \pm 5.2$ & $3210-20300$ & $2(10.5)$ \\
\hline White blood cells x103/L & $8642.6 \pm 4888.8$ & $52000-311000$ & $6(31.5)$ \\
\hline Platelet, $<109 / \mathrm{L}$ & $212578 \pm 79944.6$ & $107-293$ & $9(47.3)$ \\
\hline Total cholesterol mg/dL & $204.5 \pm 55.3$ & $8-51$ & $4(21)$ \\
\hline HDL cholesterol mg/dL & $26.4 \pm 13.9$ & $92-204$ & $9(47.3)$ \\
\hline LDL cholesterol mg/dL & $133.4 \pm 53.6$ & $88-364$ & $9(47.3)$ \\
\hline Triglycerides $\mathrm{mg} / \mathrm{dL}$ & $204.1 \pm 85.5$ & $10-849$ & $9(47.3)$ \\
\hline ALT, IU/L & $137.4 \pm 199.3$ & $16-947$ & $9(47.3)$ \\
\hline AST IU/L & $191.3 \pm 266.8$ & $0.14-7.2$ & $2(10.5)$ \\
\hline Total bilirubin $\mathrm{mg} / \mathrm{dL}$ & $1.2 \pm 1.9$ & \\
\hline
\end{tabular}

SD: Standard deviation, HDL: High-density lipoprotein, LDL: Low-density lipoprotein, ALT: Alanine transaminase, AST: Aspartate transaminase 
Mcgovern et al. (10) showed that coronary artery disease is a more common manifestation than previously reported. Additionally, Ishii et al. (13) described two young sisters with NPD-B who had myocardial dysfunction refractory to treatment. We did not detect serious cardiac involvement in our patients. It should be taken into account that only three patients were in adulthood. Acid sphingomyelinase levels were low in all our patients. This diagnosis was confirmed with SMPD1 gene analysed in 17 patients. Bone marrow biopsies were performed on 10 patients and lipid-laden foam cells were detected. The detection of vacuolated cells in peripheral blood smears or bone marrow is indicative of NPD but not exclusive to it. The diagnosis should be confirmed by enzymatic analysis and SPMD1 gene analysis (1). Bone marrow biopsies were performed on almost half of the patients although the diagnosis can be made by enzyme and molecular analysis. Keeping NPD in mind for the differential diagnosis of patients with organomegaly, cytopenia and/or pulmonary involvement may prevent the use of unnecessarily invasive procedures in the diagnostic approach. To date, $>180$ mutations have been found within the SMPD1 gene, which cause NPD-A, NPD-B. Aykut et al. (14) found one novel mutation c.1755delC (p.585PfsX24) in one of our patients and reported so in 2013. The most common mutations were previously known: c.409T>C (p.L137P) homozygous missense mutations. The L137P mutation has been linked to a less severe form NPD-B (15). In our study, patients with c.409T>C (p.L137P) also exhibited less severe symptoms. Although the p.L137P mutation is related to a less severe form, patient 5 died during adolescence due to liver failure and his brother also died prematurely (patient 6). The 573delT (p.P189fsX65) mutation had been previously identified by Gluck et al. (16). This mutation induces early onset form NPD-A (16). Manshadi et al. (17) also identified a patient with a 573delT homozygous mutation. Unusually, patient 12 had a homozygous 573delT (p.S192AfsX65) mutation and he has mild developmental delay but does not exhibit the clinical signs of early onset NPD-A. Patients with the intermediate variation between Types A and B NPD have been described (6). Patient 12 seems to be of an intermediate type. The most common Type B mutations in Turkish patients are L137P, L549P and fsP189 (15). Similarly to the literature, in total, 10 patients in our study had these mutations. Patient 3 had a common mutation for Type B but her clinically based type was similar to Type A. The patient with an A283T mutation, who was diagnosed at the age of 56 years, was clinically NPD-B. Patient 18 had compound heterozygous mutations for p.H421R and p.L137P. Although p.H421R is known to be a severe one, the combination with the L137P mutation reduced the phenotypic severity as previously reported by Aykut et al. (14). In our study, those patients with the same homozygous L137P mutations, had different clinical severity (patient 1, 2, 4, 5, 8, 9) such as patient 5, who had severe clinical findings. Some patients with NPD-B may develop life threatening complications including liver failure, hemorrhage, pulmonary infections and splenic rupture. The most common causes of disease related morbidity and mortality are respiratory and liver failure (18). Similar to our study, the deceased patients had respiratory insufficiency and patient 3 had liver failure.

BMT has been performed on some NPD patients (1). A reduction in liver and spleen size have been demonstrated. In our study, we had planned BMT for patient 1. He had a partial splenectomy operation before the planned BMT. However, during follow up, we could not perform BMT due to donor problems and his parents' subsequent decision to postpone BMT. Today, clinical trials are being conducted to determine the safety and efficacy of enzyme replacement therapy for NPD-B patients (19). There is a need for a safe and effective therapy for patients with NPD-B to reduce splenomegaly, improve liver function, decrease respiratory dysfunction and reduce mortality and morbidity.

\section{Study Limitations}

There are several limitations in this study. We investigated a small group of patients with NPD consisting of children and adults. Also, we determined the lung involvement of the patients but could not perform any functional tests.

\section{Conclusion}

Serial findings of 19 patients with ASM deficiency gave information about the natural history of the disease. The most common sign of NPD is hepatosplenomegaly. Pulmonary involvement is important for the disease's mortality and morbidity. Patients need more efficient therapies to reduce organomegaly and to improve liver and respiratory functions.

Ethics

Informed Consent: A consent form was filled out by all participants.

Peer-review: Externally peer-reviewed.

\section{Authorship Contributions}

Surgical and Medical Practices: E.C., M.Ç., Concept: E.C., S.K.U., Design: E.C., M.Ç., Data Collection and Processing: F.̈., H.O., Analysis and Interpretation: E.S., Literature Search: H.Y., E.E., Writing: E.C.

Conflict of Interest: No conflict of interest was declared by the authors.

Financial Disclosure: The authors declare that this study received no financial support.

\section{References}

1. Schuchman EH, Desnick RJ. Niemann-Pick disease types $A$ and B: acid sphingomyelinase deficiencies. In: Scriver CR, Beaudet AL, Sly WS, et al, (eds). The Metabolic and Molecular Bases of Inherited Disease. 8th ed. New York, NY: McGraw-Hill 2001:3589-610.

2. Wasserstein MP, Larkin AE, Glass RB, Schuchman $E H$, Desnick RJ, McGovern MM. Growth restriction in children with type B Niemann-Pick disease. J Pediatr 2003;142:4248.

3. Simonaro CM, Desnick RJ, McGovern MM, Wasserstein MP, Schuchman EH. The demographics and distribution 
of type B Niemann-Pick disease: novel mutations lead to new genotype/phenotype correlations. Am J Hum Genet 2002;71:1413-9.

4. McGovern MM, Pohl-Worgall T, Deckelbaum RJ, et al. Lipid abnormalities in children with types A and B Niemann Pick disease. J Pediatr 2004;145:77-81.

5. Lee CY, Krimbou L, Vincent J, et al. Compound heterozygosity at the sphingomyelin phosphodiesterase-1 (SMPD1) gene is associated with low HDL cholesterol. Hum Genet 2003; 112:552-62.

6. Schuchman EH, Desnick RJ. Types A and B Niemann-Pick disease. Mol Genet Metab 2017;120:27-33.

7. Kampine JP, Brady RO, Kanfer JN, Feld M, Shapiro D. Diagnosis of gaucher's disease and niemann-pick disease with small samples of venous blood. Science 1967;155:868.

8. ACOG Committee on Genetics. ACOG Committee Opinion No. 442: Preconception and prenatal carrier screening for genetic diseases in individuals of Eastern European Jewish descent. Obstet Gynecol 2009;114:950-3.

9. Wasserstein MP, Aron A, Brodie SE, Simonaro C, Desnick RJ, McGovern MM. Acid sphingomyelinase deficiency: prevalence and characterization of an intermediate phenotype of Niemann-Pick disease. J Pediatr 2006;149:554-9.

10. McGovern MM, Wasserstein MP, Giugliani $R$, et al. A prospective, cross-sectional survey study of the natural history of Niemann-Pick disease type B. Pediatrics 2008;122:341-9.

11. von Ranke FM, Pereira Freitas HM, Mançano $A D$, et al. Pulmonary Involvement in Niemann-Pick Disease: A Stateof-the-Art Review. Lung 2016;194:511-8.
12. Dardis A, Zampieri S, Filocamo M, Burlina A, Bembi B, Pittis MG. Functional in vitro characterization of 14 SMPD1 mutations identified in Italian patients affected by Niemann Pick Type B disease. Hum Mutat 2005;26:164.

13. Ishii $H$, Takahashi $T$, Toyono $M$, et al. Acid sphingomyelinase deficiency: cardiac dysfunction and characteristic findings of the coronary arteries. J Inherit Metab Dis 2006;29:232-4.

14. Aykut A, Karaca $E$, Onay $H$, et al. Analysis of the sphingomyelin phosphodiesterase 1 gene (SMPD1) in Turkish Niemann-Pick disease patients: mutation profile and description of a novel mutation. Gene 2013;526:484-6.

15. Simonaro CM, Desnick RJ, McGovern MM, Wasserstein MP, Schuchman EH. The demographics and distribution of type B Niemann-Pick disease: novel mutations lead to new genotype/phenotype correlations. Am J Hum Genet 2002;71:1413-9

16. Gluck I, Zeigler M, Bargal R, Schiff E, Bach G. Niemann Pick Disease type A in Israeli Arabs: 677delT, a common novel single mutation. Mutations in brief no. 161. Online. Hum Mutat 1998;12:136.

17. Manshadi MD, Kamalidehghan B, Keshavarzi F, etal. Four novel p.N385K, p.V36A, c.1033-1034insT and c.1417-1418delCT mutations in the sphingomyelin Phosphodiesterase 1 (SMPD1) gene in patients with types A and B Niemann-Pick disease (NPD). Int J Mol Sci 2015;16:6668-76.

18. McGovern MM, Lippa N, Bagiella E, Schuchman EH, Desnick RJ, Wasserstein MP. Morbidity and mortality in type B Niemann-Pick disease. Genet Med 2013;15:618-23.

19. Wasserstein MP, Jones SA, Soran $H$, et al. Successful within-patient dose escalation of olipudase alfa in acid sphingomyelinase deficiency. Mol Genet Metab 2015;116:88-97. 